\title{
The importance of neighborhood type dissonance in understand- ing the effect of the built environment on travel behavior
}

\author{
Kevin Manaugh \\ McGill University \\ kevin.manaugh@mcgill.ca
}

\author{
Ahmed M. El-Geneidy \\ McGill University \\ ahmed.elgeneidy@mcgill.ca
}

Abstract: For many years, researchers have struggled to separate the effects of personal tastes-including residential choices-from built environment and transport-related factors when attempting to understand and model travel behavior. This paper will briefly describe how issues related to self-selection, if not controlled for in a travelbehavior analysis, can lead to overestimation and underestimation of the effect of the built environment on travel behavior. A theoretical model is presented, which is followed by an empirical analysis based on survey data capturing residential choice factors to test our theory. Our analysis shows that by separating people who have chosen their current home location based primarily on transport-related concerns from people who have located based primarily on housing and neighborhood characteristics, we are able to gain a nuanced understanding of how various "costs" associated with using public transit (access time, waiting time, and transfers) affect the likelihood of taking transit. We find a strong aversion to transfers as well as different responses to these factors based on reasons for living in a given location. We demonstrate how model predictions vary greatly especially when self-selection factors are included in the analysis. Findings from this research shed light on the importance of self-selection in travel-behavior research, giving transport planners and engineers clear examples of how ignoring these factors can lead to misleading findings.

\section{Article history:}

Received: December 31, 2013

Accepted: December 30, 2014

Available online: May 29, 2015

\section{Introduction}

Various design and land-use solutions such as new urbanism, smart growth, and transit-oriented development have been offered in the past few decades with the promise of reducing automobile dependency and shifting residents of these areas to walking, cycling, and public transit. Numerous studies have found clear correlations between land-use patterns and travel behavior; however, residential selfselection - among other issues - complicates any imputation of causality. Some have argued that this higher level of mode share may be due to residential self-selection and other personal and attitudinal characteristics (Lund 2003; Cao and Chapman 2012). Put simply, do certain neighborhoods "cause" certain behaviors or do people make residential choices, at least in part, for the express purpose of

Copyright 2015 Kevin Manaugh \& Ahmed M. El-Geneidy

http://dx.doi.org/10.5198/jtlu.2015.718

ISSN: 1938-7849 | Licensed under the Creative Commons Attribution - Noncommercial License 3.0

The Journal of Transport and Land Use is the official journal of the World Society for Transport and Land Use (WSTLUR) and is published and sponsored by the University of Minnesota Center for Transportation Studies. This paper is also published with sponsorship from WSTLUR and the Institutes of Transportation Studies at the University of California, Davis, and the University of California, Berkeley. 
matching travel desires (in terms of distance and mode) with the travel options in the neighborhood?

Matching resident needs, desires, and expectations with neighborhood characteristics is clearly desirable and is arguably a goal of land-use and transport planning. Residential self-selection only becomes problematic in the context of trying to understand causality and to measure the size of the effect of design factors or infrastructure improvements or in attempting to understand or predict travel behavior in a given area based on the characteristics of local land-use and transportation infrastructure. As the debate over local, state, and federal investment in transport infrastructure, as well as their role in encouraging different types of land-use patterns continues unabated, understanding the effect of various residential and land-use patterns on behavior is vital in guiding appropriate public policy.

The importance of this from a methodological standpoint is that the population effect can be easily either overestimated or underestimated depending on how many residents are "self-selected." Cao and Chatman (2012) explore this idea conceptually and try to quantify the degree of underestimation and overestimation.

This paper explores several related issues. This paper will briefly describe how issues related to residential self-selection, if not controlled for in a travel-behavior analysis, can lead to overestimation and underestimation of the effect of the built environment on travel behavior. A theoretical model is presented, which is followed by an empirical analysis based on survey data capturing residential choice factors to test our hypothesis. The paper hypothesizes that the degree to which various desires for housing and neighborhood characteristics are factored into the decision-making process are related to the degree in which the strength of the objective aspects of the neighborhood are directly affecting behavior. To empirically examine these relationships, our analysis consists of two steps: 1) perform a cluster analysis based on the stated reason that survey respondents chose their current place of residence; and 2) examine differences in transit use among these different clusters using a standard binary logistic mode choice model to test our hypothesis explained in the framework. Finally the paper ends with a Discussion and Conclusion section, highlighting the importance of our findings and their policy relevance.

\section{Context and literature review}

As Chatman (2009) and Naess (2009) have pointed out, the built environment can directly affect behavior even in the presence of residential self-selection by providing a desired setting to engage in desired travel patterns. If preferred neighborhood styles are underrepresented in the housing market, then it could be argued that the built environment could have a significant effect on behavior by meeting this latent demand. In this context, it is important to emphasize the distinction between "affecting" and "changing" behavior. The built environment clearly "affects" the behavior of someone who moves to a neighborhood to travel by certain modes; however, the built environment, in this case, did not "change" behavior, instead it made it possible.

This can also be illustrated through the concept of neighborhood mismatch (Schwanen, and Mokhtarian 2005). A "mismatched suburbanite" who drives more often than her or his preferred mode of cycling is being affected by the built environment and physical design of the neighborhood. By relocating to a location with a higher density and plentiful cycle paths in order to cycle more often, this "mismatched suburbanite" can become a "matched urbanite." In which case, the built environment allows her to fulfill the cycling preference, without changing her transport-related preferences. On the other hand, a "mismatched urbanite" might, over time, begin to use, and even prefer, public transit due to its ease and convenience in his or her current location. These two separate effects of the built environment are part of a complex process. Both effects are important in understanding behavior. A neighborhood of "matched" suburbanites is unlikely to respond to increased transit accessibility in the same way as a neighborhood of "mismatched" suburbanites is (Schwanen and Mokhtarian 2007). These relationships 
and processes exist regardless of scale or unit of analysis. At an individual or household level, regression coefficients, for example, are likely to be underestimated or overestimated, while predictions at a neighborhood level will vary by the degree of neighborhood-type dissonance.

As households do not randomly distribute throughout a region, understanding residential sorting, and reasons and motivations behind residential choices is vital. People make residential decisions for a wide variety of reasons. The relative importance of different factors is likely to vary widely across individuals as well as within households. Figure 1 shows a schematic diagram of how various preferences and desires for housing and neighborhood type might impact actual home location and travel behavior. While simplified, this figure identifies four main groups of factors related to the "bundle" of housing. Location and budget constraints refer to financial and geographical limits on where to live.

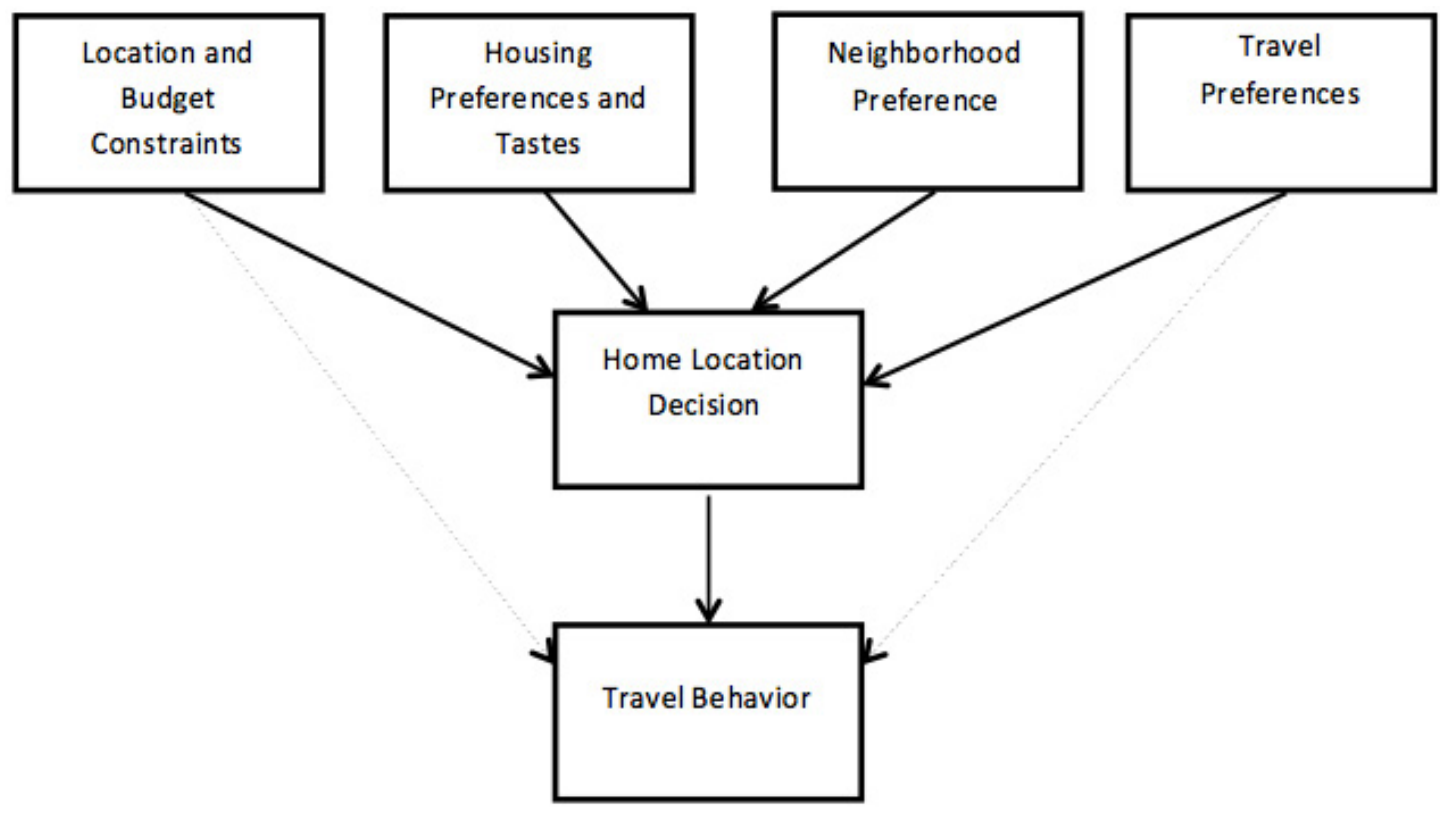

Figure 1: Influences on home location and travel behavior

Obviously, most people cannot afford to live wherever they want, and the location of employment, daycare and school for children, for example, also play a significant role in deciding where to locate. For potential homes that fall within a household's spatial and financial boundaries, other factors come into play such as preferences for housing, preferences for certain types of neighborhoods, and preferences for travel. Each household, however, will not only have different preferences and tastes, but will also "weight" the importance of these various aspects differently. Furthermore, in addition to households valuing these factors differently, households with similar preferences can have mismatch or dissonance in any or all of these dimensions. De Vos et al (2012) explore many of the reasons why a household may not locate in the most desired location. These include intra-household dynamics in addition to more obvious financial constraints - which are also more likely to occur for low-income households. Figure 1 also shows the impacts of these factors both directly (in the case of budget and travel preferences) and indirectly (through the residential location decision) on travel behavior.

\subsection{Values related to transportation}

Let us assume that there are two different attitudes associated with transit use within society. We will call these attitudes or predispositions "transit friendly" and "transit resistant." The former category would be 
composed of those who for various environmental, economic, social, or other reasons might intrinsically value and use public forms of transportation. While the "transit resistant" group, for other reasons (value of time, privacy, etc.), might prefer other modes. Of course, these values would exist on a continuum; we will use the extremes for simplicity's sake. In terms of modeling behavior in a mode-choice model, for example, researchers would likely be interested in the magnitude of the coefficients associated with the various time and effort costs such as walking time, waiting time, and number of transfers involved in the decision to use public transit. Other factors might also be of interest such as slope of walk, quality of sidewalks, views, safety, and so on. However, one could easily error in estimating the parameter of walking distance to transit if one does not know the proportions of various attitudes toward transit, and toward walking among the studied population. Let us imagine that research into mode share of transit (which failed to account for self-selection) found that an increase of 100 meters of walking distance to a transit stop was associated with a 10 percent decrease in the likelihood to take transit. If these findings were used to predict transit ridership in a different neighborhood, several outcomes would be possible based on the degree to which the populations match. This is illustrated in Table 1. If the findings of research into "self-selected" transit users are used to predict transit ridership in a neighborhood of transit resistant residents, coefficients associated with walking time are likely to be underestimated and predictions for use are likely to be over-estimated. Just as important, even if predictions might be consistent across like groups, regression coefficients would overestimate or underestimate the "true" population parameter based on the underlying opinions and attitudes toward transit in the sampled population. Regression coefficients derived from a sample of transit-resistant residents would underestimate the impacts of the built environment and potentially underestimate transit predictions for a more transitreceptive population.

Table 1: Transit usage example

\begin{tabular}{|c|c|c|c|}
\hline & \multicolumn{3}{|c|}{ “Target" Population } \\
\hline & & Transit oriented & Transit resistant \\
\hline \multirow{2}{*}{ 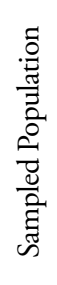 } & transit oriented & $\begin{array}{l}\text { Consistent prediction, } \\
\text { overestimated effect of built } \\
\text { environment }\end{array}$ & $\begin{array}{l}\text { Overestimated predictions, } \\
\text { overestimated effect of built } \\
\text { environment }\end{array}$ \\
\hline & transit resistant & $\begin{array}{l}\text { Underestimated predictions, } \\
\text { Underestimated effect of built } \\
\text { environment }\end{array}$ & $\begin{array}{l}\text { Consistent prediction, } \\
\text { underestimated effect of built } \\
\text { environment }\end{array}$ \\
\hline
\end{tabular}

In other words, someone who intrinsically values taking transit for environmental, financial, or social reasons will likely have a much higher "tolerance" for the time and effort costs mentioned previously. On the other hand, a person who does not value transit—and makes home location decisions based on non-transport-related factors - could very well live within a few hundred meters of a transit stop with a direct and easy trajectory to a desired destination and still prefer to drive.

\subsection{Residential location factors}

Figure 2 presents factors related to home location and a hypothesized view of the variance of the strength of built environment effects as the relative weighting of various elements of residential choice. We hypothesize that the direct effect of the built environment and/or transportation characteristics will increase the more home-location factors are influenced by constraints and housing desires relative to travel and neighborhood preferences. 


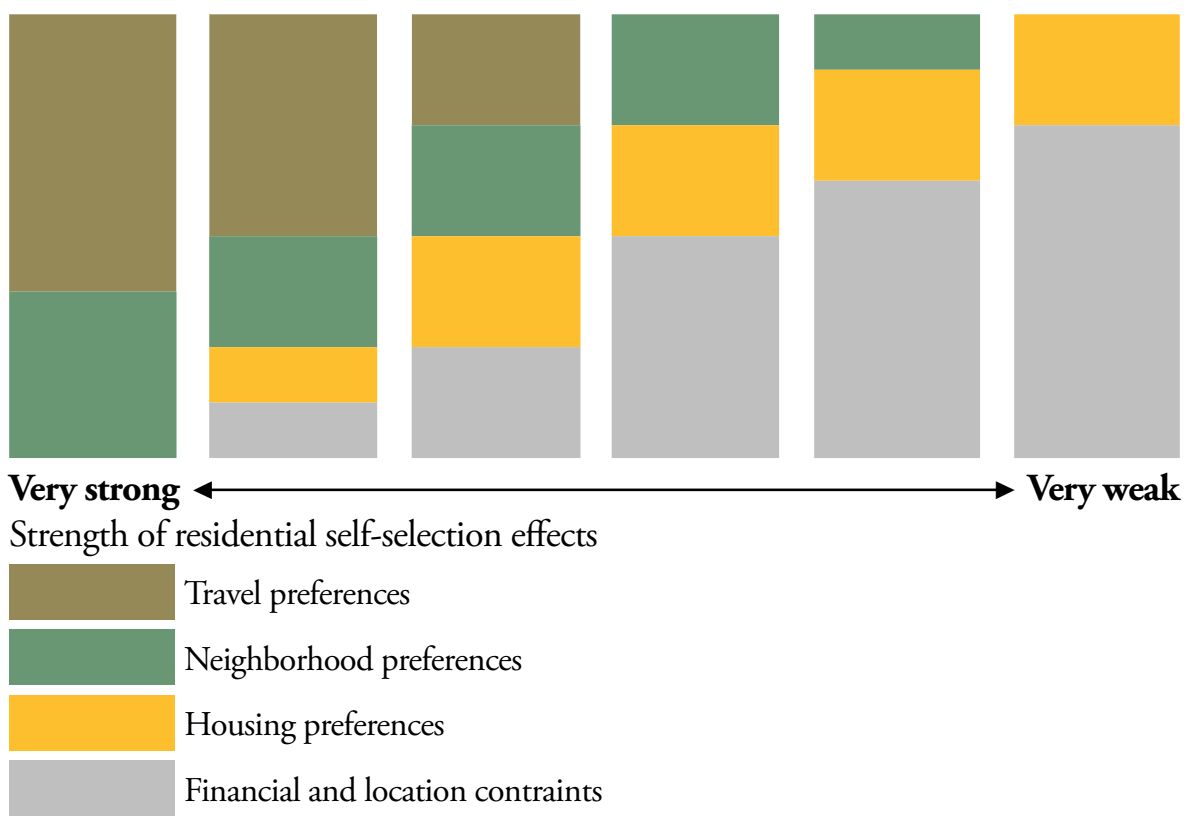

Figure 2: Neighborhood choice factors and hypothesized strength of the effect of the built environment

We can further hypothesize that the relative weight of these various factors as well as how well these preferences are matched is a fundamental aspect of how much impact the built environment has on travel behavior. The following sections present an attempt to explain and model these relationships through an analysis of a transit mode choice among commuters from a travel survey using various statistical techniques.

\section{Data methodology}

The data used in this research were obtained from a travel behavior survey carried out at McGill University in Montreal, Quebec, Canada, in consultation with members of the Office of Sustainability of McGill Campus and Space Planning, as well as members of the McGill IT Office. An invitation to participate in the survey was distributed via email to a random sample of faculty, staff, and students, providing recipients with a link to the online survey. The survey remained active for a total of 35 days during March and April 2011, during which a total of 19,662 survey invitation emails were distributed among the university community. For geocoding purposes, respondents were asked to indicate the postal code at their place of residence as well as the area of campus at which they spend the majority of their time while at McGill. It is important to note that Canadian postal codes are quite fine-grained, corresponding to a single block face. A typical block will have four postal codes; therefore, the margin of error is approximately plus or minus 100 meters for most of the city. The response rate for the survey was 25.5 percent, which is comparable to previous studies in university settings.

In this study, we concentrate on measuring the impacts of self-selection on mode choice, specifically choosing to use transit instead of an automobile. Therefore, in response to "Describe the sequence of your most recent trip to McGill by answering the following questions: First, I [respondent is given a choice of several modes of transportation including walking, cycling, transit, driving]," we select only those commuters sho employ either of these two modes in our analysis, giving a sample size of 1820 . Of these, 1193 (65.8 percent) commute using transit while the remaining 627 (34.2 percent) commute by car. To capture the transit attributes, Google Maps was used to generate the fastest transit alternative 
available to each individual at the time of his/her departure. This also entailed collecting access (walking) time, waiting time, number of transfers, and time spent on various forms of transport (bus, subway, or train).

Respondents were further asked to select the "most important" and "second most important" element motivating their residential-location decision. The possible responses (in addition to an "other" category) included elements of the walkability of the neighborhood, proximity to transit, amenities in the neighborhood, proximity to family and social networks, and quality of schools. Constraints include responses dealing with finances as well as "the decision was out of my control" to capture the situation for students, for example.

To understand the relationships between residential choice factors and behavior, individual respondents are clustered (using two-step clustering in SPSS) by their cited reasons for choosing their current location. Binary logistic regression is employed on the pooled dataset as well as on each of the resulting seven clusters.

\section{$4 \quad$ Findings}

This section will present the findings starting with an analysis of the residential choice factors before moving on to the clustering results. After this the regression analysis is presented for a pooled model incorporating all clusters without any differentiations based on home-location choices. This is followed by a series of statistical models that are stratified based on the clusters to show the differences in the coefficients of the statistical models compared to the general model. Finally we conduct a sensitivity analysis to illustrate the relationships among the variables of interest to show the variance in mode-choice probabilities among the different groups under different scenarios and compare that to the pooled model.

\subsection{Residential location results}

Figure 3 shows the responses to the residential choice questions by percentage. Not surprisingly, the housing quality, cost of housing, neighborhood amenities, and proximity to transit are the most commonly cited reasons. This figure shows percentages of respondents who cited each of these aspects as either the "first" or "second" most important reason for their current location. In other words, 20 percent of the sample cited "housing quality" as their most important criteria, while an additional roughly 17.5 percent cited it as their second most important, for a total of 37.5 percent who mentioned this factor. Interestingly, and perhaps indicative of our sample, many respondents cited lack of control in the decision-making process. 


\section{Percentage of residential location factors}

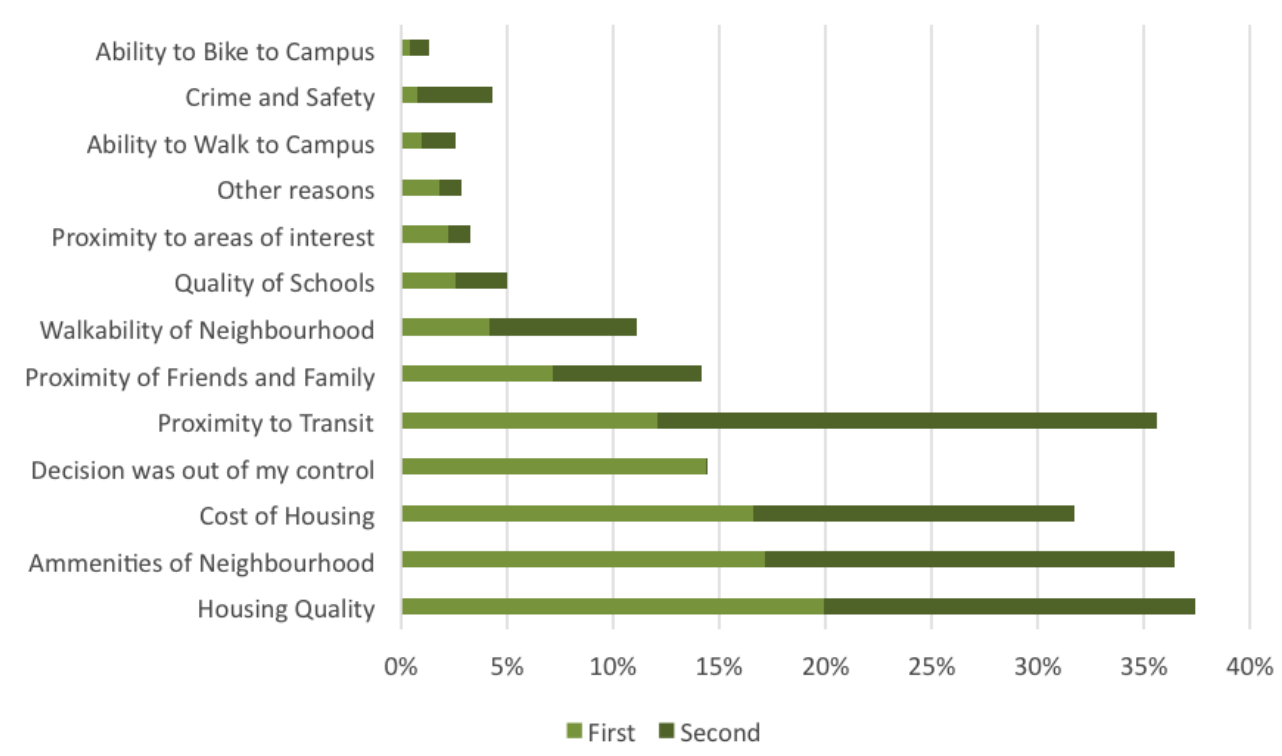

Figure 3: Residential choice factors by percentage

\subsection{Cluster analysis}

The next step was to cluster respondents to be able to test our hypothesis that different types of people show a different response to various time and effort costs associated with using transit. By clustering at the individual level using home-location choice variables we see that there is great variance in the reasons given to live in the current residence. Two-step clustering is well-suited to identifying groups by minimizing in-group variance and maximizing across-group variance. As we later planned on using variables such as age and gender, as well as objective elements of the trip (distance, time, number of transfers), these variables were not included in the cluster analysis. Only the responses to the residential choice questions are included in the cluster analysis; in this way, respondents were categorized by their "first" and "second" most important reason for living in their current location. The clusters were quite distinct with a silhouette coefficient of 0.88 (Norusis 2010). Figure 4 shows the percentages of respondents in each residential choice category. After finding a reasonable cluster outcome, the resulting clusters were named according to their characteristics. It is important to understand that figure 4 shows the percentage of "responses" to the survey; therefore, it includes two responses from each individual. This means that, for example, roughly 50 percent of the responses in the "self-selected transit users" were concerned with matching the desire to use transit: 25 percent mentioned neighborhood characteristics, 13 percent listed housing elements, and 12 percent chose geographical or financial constraints. In other words, 100 percent of the people in the "self-selected transit user" cluster chose "proximity to transit" as either the first or second most important residential choice factor. We hypothesize that these household clusters show a continuum of self-selection effects, with those toward the left of the figure less directly affected (or changed) by elements to the right of the figure, thus the built environment and transport characteristics play a more direct role in influencing behavior. 


\section{Cluster Results}

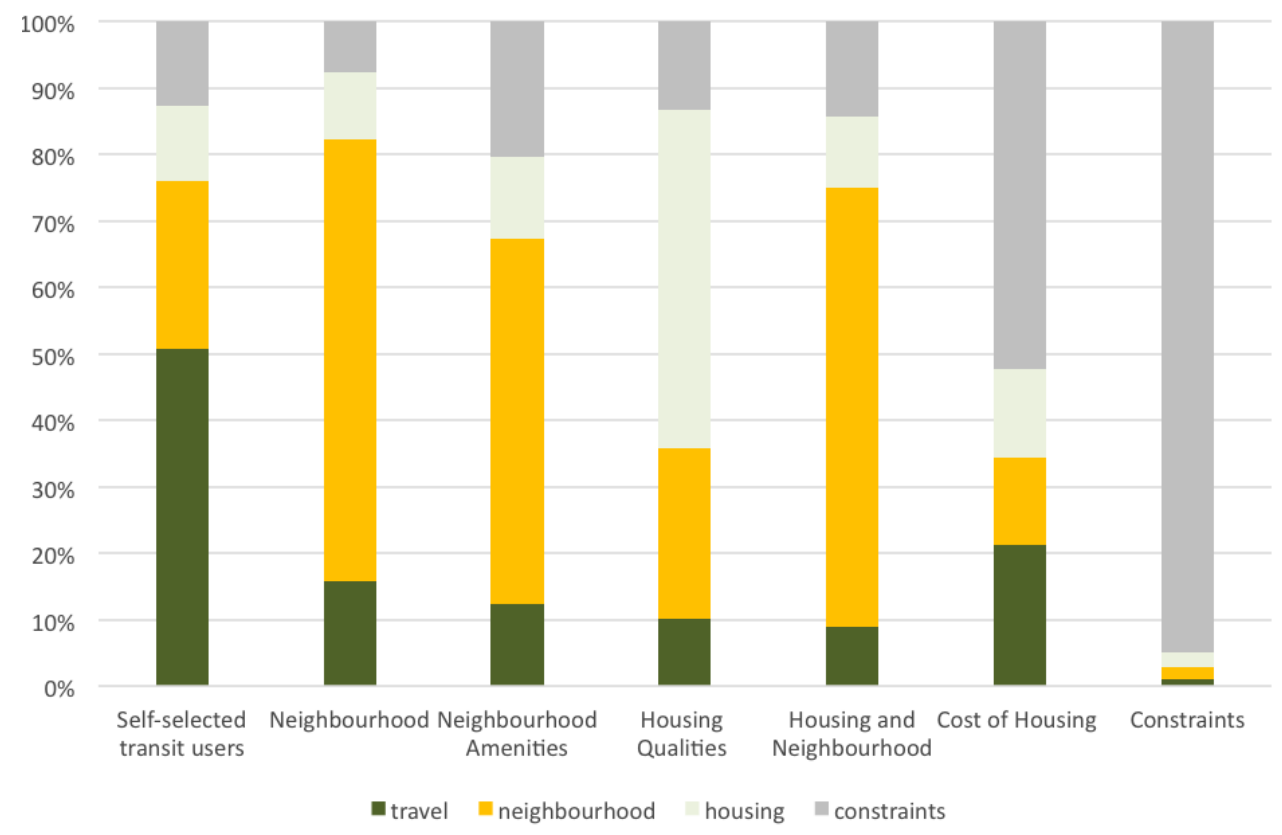

Figure 4: Description of clusters

Table 2 shows additional detail about the clusters including number of observations in each cluster, transit share, and details about the transit offer. It is important to note that we are using a sample from an urban, university setting, so the percentages of each cluster compared to the entire population might be different in the region as a whole, yet each of these clusters is expected to be present in the general population. We observe variance in the transit rate as well as in objectively measured elements of the transit trips. The lower-than-average number of transfers, waiting time, and access time for the selfselected transit cluster, for example, point to both a "match" of residential desires as well as a rational decision toward using transit in this group. As well, the group with the highest average waiting time, access time, and number of transfers (the "housing-oriented" cluster) show the lowest rate of transit use. The regression results below explore these relationships in much more detail.

Table 2: Transit route characteristics by cluster

\begin{tabular}{|l|r|r|r|r|r|}
\hline & COUNT & $\begin{array}{c}\text { TRANSIT } \\
\text { SHARE }\end{array}$ & $\begin{array}{c}\text { AVERAGE } \\
\text { TRANSFERS }\end{array}$ & $\begin{array}{c}\text { AVERAGE } \\
\text { WAITING } \\
\text { TIME }\end{array}$ & $\begin{array}{c}\text { AVERAGE } \\
\text { WALKING } \\
\text { TIME }\end{array}$ \\
\hline SELF-SELECTED TRANSIT USERS & 220 & $95.5 \%$ & 0.53 & 2.24 & 5.44 \\
\hline NEIGHBORHOOD ORIENTED & 311 & $61.4 \%$ & 0.64 & 2.22 & 6.06 \\
\hline AMENITIES NEIGHBORHOOD & 234 & $55.1 \%$ & 0.63 & 2.21 & 5.73 \\
\hline HOUSING ORIENTED & 362 & $46.7 \%$ & 0.93 & 3.74 & 6.90 \\
\hline AMENITIES/HOUSING & 130 & $56.9 \%$ & 0.97 & 2.83 & 5.88 \\
\hline HOUSING COST & 302 & $73.5 \%$ & 0.76 & 2.89 & 6.51 \\
\hline CONSTRAINTS & 261 & $75.9 \%$ & 0.87 & 3.12 & 6.30 \\
\hline
\end{tabular}




\subsection{Regression analysis}

This section explores the rationale for and the results of the binary logistic regression analysis. Binary logistic regression analysis is commonly used to understand decision making and is well-suited for our analysis of mode choice limited to a sample of transit and car users. First, Table 3 shows descriptive statistics for each of the variables included in the analysis.

For ease of interpretation, we report the odds ratio. An odds ratio implies a change in probability of $\beta-1$ for each unit change in X. In other words, an odds ratio of 1.081 would indicate an 8.1 percentage point increase in the probability of taking transit, while an odds ratio of 0.929 indicates a decrease in the probability by 7.1 percentage points.

Table 3: Descriptive statistics for all variables in model

\begin{tabular}{|l|r|r|r|r|r|}
\hline & \multicolumn{1}{c|}{ Unit } & \multicolumn{1}{c|}{ Min } & \multicolumn{1}{c|}{ Max } & \multicolumn{1}{c|}{ Mean } & \multicolumn{1}{c|}{ SD } \\
\hline TOOK TRANSIT & Yes/No & 0.00 & 1.00 & 0.66 & 0.48 \\
\hline MALE & Yes/No & 0.00 & 1.00 & 0.62 & 0.49 \\
\hline AGE & Years & 18.0 & 81.0 & 40.4 & 14.2 \\
\hline DURATION & Minutes & 2 & 175 & 42.86 & 22.424 \\
\hline TIME IN BUS & Minutes & 0 & 96 & 13.77 & 14.113 \\
\hline TIME IN METRO & Minutes & 0 & 27 & 5.20 & 6.631 \\
\hline TIME IN TRAIN & Minutes & 0 & 68 & 5.05 & 11.739 \\
\hline TOTAL WAITING & Minutes & 0 & 39 & 2.81 & 3.763 \\
\hline WALKING TIME & Minutes & 0 & 58 & 6.21 & 5.028 \\
\hline TRANSFERS & Count & 0 & 5 & .76 & .835 \\
\hline N=1820 & & & & & \\
\hline
\end{tabular}

The pooled model shows results consistent with expectations. Access time, waiting time, number of transfers, and time spent on a bus are all statistically significant and have negative coefficients. The bus time finding is interesting as it quantifies the resistance to taking a bus. While controlling for all other variables, one minute on a bus for a potential transit trip is associated with a 5.1 percent decrease in the probability of taking transit. Other forms of transit are insignificant in the model. Age and age squared are both statistically significant. When plotted, we see that age has a negative influence on the likelihood to use transit until around age 50 when the trend reverses, which is captured through both coefficients. Being male and the total duration of the trip are not significant. Possession of a driver's license, holding all other variables constant at their mean values, has a large and statistically significant relationship with transit use and is associated with a decrease of 88 percent in the likelihood of taking transit. The odds ratios associated with access time and waiting time are statistically significant and with negative coefficients. Each additional minute or access (walking) time or waiting time is associated with a 6.4 percent and 8.3 percent decrease in the probability of taking transit, respectively, while keeping all values constant at their means. Finally, transfers play a large and statistically significant role in discouraging commuters to use transit. The 95 percent confidence interval is also shown in the table; these values will be important when discussing the separate models below. 
Table 4: Pooled regression results

\begin{tabular}{|l|r|r|r|}
\hline & & \multicolumn{2}{|c|}{$\mathbf{9 5 \%}$ Confidence } \\
\hline & Odds Ratio & \multicolumn{1}{|c|}{ Lower } & \multicolumn{1}{c|}{ Upper } \\
\hline Male & $\mathbf{1 . 1 0 4 2}$ & 0.8651 & 1.4094 \\
\hline Age & $\mathbf{0 . 7 8 6 7}$ & 0.7436 & 0.8322 \\
\hline age2 & $\mathbf{1 . 0 0 2 1}$ & 1.0015 & 1.0028 \\
\hline Driver license & $\mathbf{0 . 1 2 9 1}$ & 0.0676 & 0.2465 \\
\hline Duration & 1.0045 & 0.9756 & 1.0341 \\
\hline Transfers & $\mathbf{0 . 5 8 6 7}$ & 0.4475 & 0.7692 \\
\hline Time in bus & $\mathbf{0 . 9 4 9 5}$ & 0.9198 & 0.9802 \\
\hline Time in metro & 1.0296 & 0.9896 & 1.0713 \\
\hline Time in train & 1.0087 & 0.9717 & 1.0471 \\
\hline Waiting time & $\mathbf{0 . 9 1 7 7}$ & 0.8682 & 0.9701 \\
\hline Access time & $\mathbf{0 . 9 3 6 5}$ & 0.9007 & 0.9737 \\
\hline
\end{tabular}

Nagelkerke R2=0.392

Bold indicates statistically significant at 99 percent confidence level

\subsection{Separate models}

To further understand these relationships, we ran seven separate models—one for each cluster. Each cluster was run with the same control variables as the pooled model but only the variables of interest are shown in Table 5, which highlights those variables that are significant in the stratified models. Self-selected transit users and the neighborhood-amenities clusters show a response respectively lower and higher to each minute of waiting time. The housing-oriented cluster has a much larger response to transfers than the pooled model. Two of the clusters, neighborhood oriented and neighborhood amenities, do not have significant coefficients for the variables of interest; however, they are shown in the table for reference.

Table 5: Coefficients from stratified models

\begin{tabular}{|l|r|r|r|r|}
\hline & \multicolumn{1}{|c|}{ Transfers } & \multicolumn{1}{c|}{ Waiting } & \multicolumn{1}{c|}{ Walking } & \multicolumn{1}{c|}{$\mathbf{R}^{\mathbf{2 1}}$} \\
\hline All & $0.587^{*}$ & $0.918^{*}$ & $0.936^{*}$ & 0.392 \\
\hline Self-selected transit users & 0.315 & $0.987^{*}$ & 0.863 & 0.402 \\
\hline Neighborhood oriented & 0.729 & 1.047 & 1.008 & 0.337 \\
\hline Amenities neighborhood & 0.768 & 0.885 & 1.049 & 0.377 \\
\hline Housing oriented & $0.292^{*}$ & 0.920 & $0.919^{*}$ & 0.376 \\
\hline Amenities/housing & 1.336 & $0.719^{*}$ & 0.937 & 0.330 \\
\hline Housing cost & $0.511^{*}$ & 0.924 & 0.902 & 0.462 \\
\hline Constraints & 0.861 & $0.850^{*}$ & $0.902^{*}$ & 0.464 \\
\hline
\end{tabular}

1Nagelkerke R2

${ }^{*} \mathrm{p}<0.001$

To better visualize the relationships among residential choice, characteristics of the transit offer, and actual transit use, Figure 5 shows the predicted probability of using transit given various scenarios. Using the mean value for all control variables, the variables of interest were manipulated to understand how different people in different clusters might respond to different transit situations. We predict the probability of a 40-year-old man with a driver's license when deciding whether to use a transit trip for a total 
of 42 minutes (inclusive of in-vehicle time, access, and waiting time) under different scenarios of access time, waiting time, and number of transfers. These scenarios are arranged in order (left to right) from most to least convenient. Based on the mean values for access and waiting time, 30 seconds was added to each in order to understand the response to these factors. This is accomplished using the "predict" command in STATA. Many noteworthy patterns can be seen, and the figure allows for the visualization of the differing response to these time and effort costs. For example, the constraints cluster shows almost no response to transfers, showing a similar probability with 4.5 minutes and 3 minutes access time and waiting time respectively with one transfer as a trip involving no transfers and a longer access (5.5. minutes) and wait time (2.5 minutes). On the other hand, those who chose their current location based primarily on housing costs show a much larger response to transfers while showing a similar slope for waiting and access time. Self-selected transit users, not surprisingly, show very high rates of use (and predicted probabilities).

Also, returning to the constraints cluster, we observe that this group shows a relatively "flat" response. Under optimal conditions (no transfers and low access time, for example) the pooled model housing-oriented and neighborhood-amenities clusters all show a higher probability of using transit than the constraints cluster. However, interestingly, all of these groups eventually show a lower probability as the scenarios get less convenient.

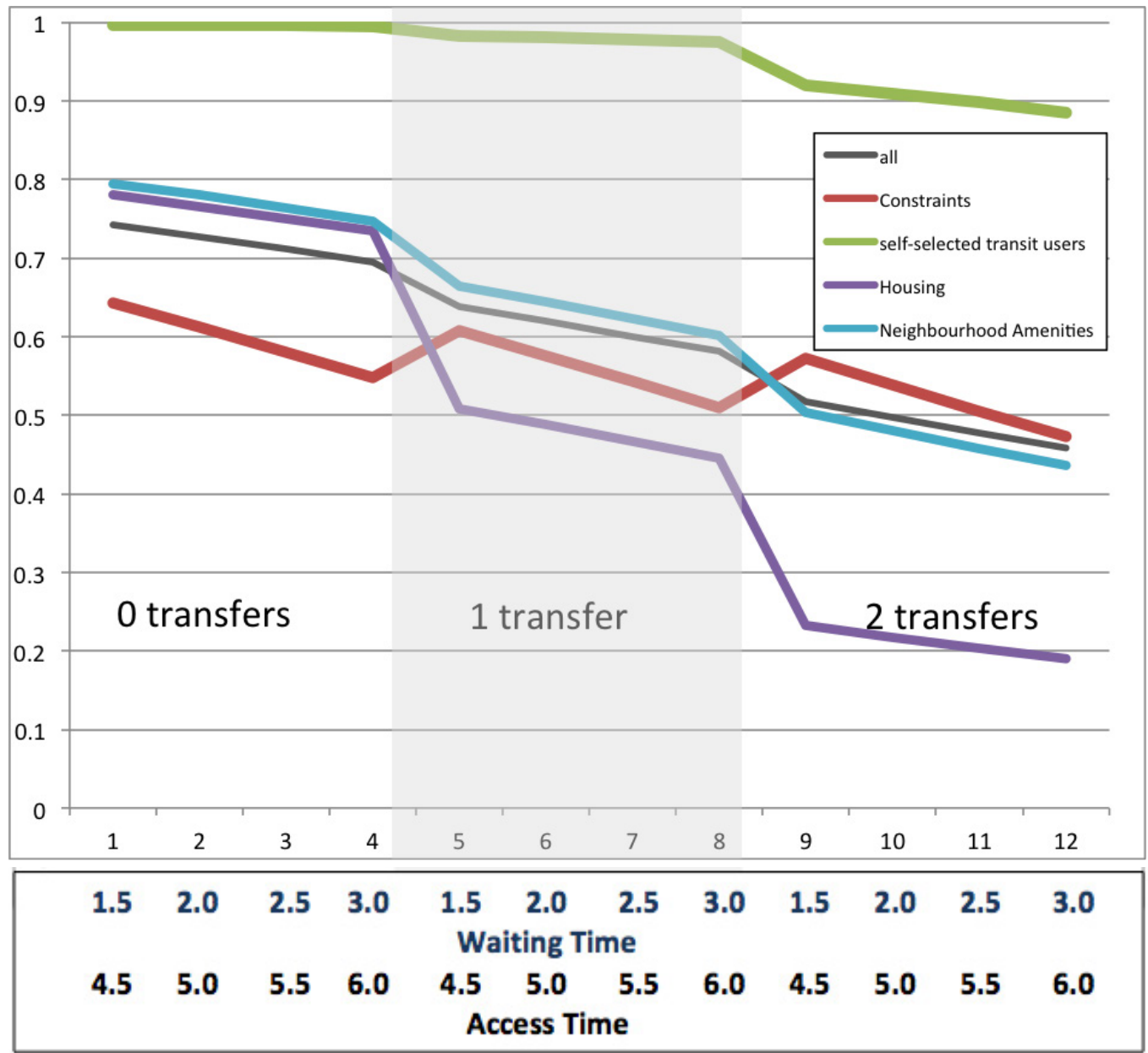

Figure 5: Predicted probabilities of using public transport from model outputs 


\section{$5 \quad$ Discussion and conclusion}

This paper describes some conceptual considerations in regard to the interaction of preferences for certain aspects of the housing bundle, travel choices, home-location choices, and the strength of the built environment and transportation characteristics on behavior. An analysis shows that there are clear clusters of households that weigh various aspects of the housing decision differently. This is important in gaining a deeper, more nuanced picture of how these elements interact to influence behavior.

The pooled regression results confirm some intuitive concepts about the decision to use public transit. Access time, waiting time, and number of transfers work as barriers to using transit. Minimizing these time and effort costs could go a long way to encourage more use of transit. Interestingly, the coefficient associated with time spent on a bus highlights the unattractiveness of this mode of transport. The clustering of respondents reveals further nuances in the relationships among home-location factors, transit supply, and use.

At the most basic level, this analysis shows that indeed different people respond differently to various elements related to the built environment and transit supply. This is not terribly surprising in and of itself but becomes interesting in the context of separating the effects of residential self-selection (and other aspects of tastes and preferences) from strictly physical or objective influences on travel choices. Tables 4 and 5, for example, provide evidence that a mode-choice model run on a sample that does not account for residential choice effects can underestimate the strength of coefficients and overestimate predicted transit use. This is more clearly seen in Figure 5, the influence of the self-selected transit users affects the prediction of the all (pooled) category. The findings, in general, support our research framework and hypothesis; we see a marked difference in the response to variables associated with the ease or practicality of taking transit. The inclusion of self-selected transit users can misrepresent the experience or disincentive of time and effort costs on more transit-resistant populations. In other words, a sample that includes self-selected transit users might underestimate the power of time and effort costs in using transit. Therefore, convincing or enticing people to stop driving and use transit for daily commutes may be more difficult than simply recreating the current ease and practicality experienced by current transit users.

Improved land use and transport policy depends on understanding more accurately the effects of the built environment on travel choices and behavior. This paper argues that it is vital to understand the potential thresholds for those who may be more resistant to transit. We argue that by isolating people who have made a residential choice based primarily on transit proximity from those who value other aspects of the hosing bundle will give the most accurate analysis of the strength of physical neighborhood characteristics on travel behavior. It is important to reiterate that the potential overestimation of the direct effect of the environment does not diminish the importance of ensuring that a supply of housing and neighborhood matches those who wish to travel by certain modes. While proponents of dense, mixed-use neighborhoods, for example, often at least implicitly claim that these factors are "influencing" behavior, it may be just as important that these areas allow desired behaviors to happen. The notions we observed in this analysis are expected to be the same with other modes and when measuring travel behavior in general. More research is needed in this direction to confirm the findings using different travel behavior measures. Findings from this research shed light on the importance of self-selection in travel behavior research, giving transport planners and engineers clear examples of how ignoring these factors can lead to misleading findings. Looking at other modes such as walking and cycling and other travel outcomes (such as distance, time, and frequency) is important to further test the hypothesis presented herein.

The analysis presented here points toward some interesting questions for future research. In particular, understanding the multi-faceted nature of home location decisions and the many dimensions that 
households can be consonant or dissonant with a neighborhood is a rich area for research. Recent trends in research design and modeling frameworks are promising in the sense of better capturing not only the "what" but also the "why" of travel behavior. It is especially important to understand these relationships over time through longitudinal and before and after studies.

\section{References}

Cao, X., and D. Chatman. 2012. How will land use policies affect travel? The importance of residential sorting. Paper presented at the Transportation Research Board Annual Meeting, January 22-26 Washington, DC.

Chatman, D. 2009. Residential choice, the built environment, and nonwork travel: Evidence using new data and methods. Environment and Planning A 41(5).

de Vos, J., B. Derudder, V. Van Acker, and F. Witlox. 2012. Reducing car use: Changing attitudes or relocating? The influence of residential dissonance on travel behavior. Journal of Transport Geography 22: $1-9$.

Lund, H. 2003.Testing the claims of new urbanism: Local access, pedestrian travel, and neighboring behaviors, Journal of the American Planning Association 69:4: 414-429.

Naess, P. 2009. Residential self-selection and appropriate control variables in land use: Travel studies. Transport Reviews 29(3): 293-324.

Norusis, M. 2010. PASW Statistics 18 Guide to Data Analysis. Upper Saddle River, N.J: Prentiss Hall.

Schwanen, T., and P. Mokhtarian. 2005. What if you live in the wrong neighborhood? The impact of residential neighborhood type dissonance on distance traveled. Transportation Research Part D 10(2): $127-151$.

Schwanen, T., and P. Mokhtarian. 2007. Attitudes toward travel and land use and choice of residential neighborhood type: Evidence from the San Francisco bay area. Housing Policy Debate 18(1): 171-207. 